\title{
KINERJA PUSAT PELATIHAN PERTANIAN PERDESAAN SWADAYA BERBASIS PESANTREN DI JAWA BARAT
}

\section{THE PERFORMANCE OF PESANTREN-BASED OF FARMER'S AGRICULTURAL AND RURAL TRAINING CENTER IN WEST JAVA}

\author{
Solihin*1,2, Iwan Setiawan², Eliana Wulandari' \\ ${ }^{1}$ Pusat Pelatihan Pertanian, Badan PPSDMP, Kementerian Pertanian \\ Jl. Harsono RM No. 3 Ragunan Pasar Minggu, Jakarta 12550 \\ ${ }^{2}$ Fakultas Pertanian, Universitas Padjadjaran \\ Jl. Raya Bandung-Sumedang KM. 21 Jatinangor, Jawa Barat 45363 \\ *E-mail corresponding: maslihin1@gmail.com \\ (Diterima 10-07-2019; Diterima 22-07-2019)
}

\begin{abstract}
ABSTRAK
Pesantren selama ini hanya diidentikkan dengan lembaga pencetak ulama atau pemikir agama. Pesantren pada saat ini telah bertransformasi menjadi salah satu lembaga penyedia sumber daya manusia (human resource) di segala bidang. Sektor pertanian merupakan lembaga yang mandapatkan manfaat perubahan tersebut melalui Pusat Pelatihan Perdesaan Swadaya (P4S) berbasis pesantren. P4S selama ini diidentikkan sebagai lembaga milik dan lahir dari keswadayaan petani, namun ternyata banyak masalah atau kendala yang dihadapi, diantaranya adalah ketergantungan terhadap bantuan pemerintah, keterbatasan jejaring kemitraan, bagaimana menjaga kontinuitas usaha, pemasaran produk, serta diversifikasi usaha. Penelitian ini bertujuan untuk mengetahui peran dan kinerja P4S berbasis pesantren. Analisis yang digunakan yaitu statistik deskriptif dengan jumlah responden sebanyak 140 orang anggota P4S. Hasil penelitian menunjukkan bahwa P4S berperan dalam kategori tinggi dan sedang, yang berarti P4S kurang berperan maksimal pada sebagian kegiatan. Sedangkan kinerja P4S dalam kategori sedang, hal ini menandakan bahwa P4S tidak berkinerja baik pada semua indikator.
\end{abstract}

Kata kunci: P4S, Peran, Kinerja, Swadaya, Pesantren

\section{ABSTRACT}

Pesantren have only been identified with the institutions of printing scholars or religious thinkers. Now it has been transformed into one of the human recourse institutions in all fields. The agricultural sector is one of the institutions that benefited from this change through the pesantrenbased Self-suppoter Farmer's Agricultural and Rural Training Center (FAR-TC). FAR-TC has been identified as an institution and was born from farmers' self-reliance, but it turns out that many problems or obstacles have been faced, including dependence on government assistance, limited partnership networks, how to maintain business continuity, product marketing, and business diversification. This study aims to role and determine the performance of Pesantren-based FAR$T C$. Research metode in this case is description statistics which the number responden are 140 member/component of FAR-TC. The results showed that P4S had a role in the high and medium categories, which meant that FAR-TC had a minimum role in some activities. While the performance of FAR-TC is in the moderate category, which indicates that FAR-TC does not perform well on all indicators.

Keywords: FAR-TC, Role, Performance, Self-Help, Pesantren 


\section{KINERJA PUSAT PELATIHAN PERTANIAN PERDESAAN SWADAYA \\ BERBASIS PESANTREN DI JAWA BARAT \\ Solihin, Iwan Setiawan, Eliana Wulandari}

\section{PENDAHULUAN}

Pesantren yang dahulu dikenal hanya sebagai tempat pembelajaran ilmu keagamaan secara tradisional (diniyyahsalafiyah), dominan dengan figur kyai, dan mencetak ulama (Yasid dkk, 2018; Hamzah, 2015). Kini pesantren telah melakukan transformasi dengan jenis dan sistem pendidikan lainnya secara terpadu, sehingga terjadi perubahan paradigma (Dhofier, 2011). Menurut Suwito (2008), proses perubahan paradigma itu sudah dimulai sejak tahun 1970an. Lahirnya UU No. 20 tahun 2003 tentang Sistem Pendidikan Nasional, PP No. 55 tahun 2007 tentang pendidikan agama dan keagamaan, dan Peraturan Menteri Agama No. 3 tahun 2012 tentang Pendidikan Keagamaan Islam, memperkuat proses transformasi pesantren sehingga kini tidak hanya berfungsi sebagai sumber pengkaderan pemikir-pemikir agama (ulama) dan lembaga pencetak sumber daya manusia, "faqih fi 'ulum ad din dan faqih $f i$ mashalih al ummat”. Saat ini pesantren juga mampu menghasilkan sumber daya manusia yang berpengetahuan luas dan handal (human resourse), menguasai segala bidang ilmu pengetahuan dan mampu menyatukan ilmu-ilmu agama dengan ilmu umum yang menyangkut kehidupan masyarakat. Dampaknya, kini pesantren juga mempunyai kekuatan dalam melakukan pemberdayaan pada masyarakat (community empowerment), sehingga dapat berfungsi sebagai lembaga pemberdaya pada masyarakat (community empowerment). Sebab itulah, saat ini pemerintah dengan berbagai pendekatan kelembagaan telah memberikan perhatian khusus pada dunia pesantren dengan berbagai program.

Mewujudkan salah satu fungsi pesantren sebagai lembaga pemberdaya pada masyarakat (community empowerment) bukanlah perkara mudah. Namun, dengan melihat potensi besar pesantren sebagaimana terurai di atas tentu ada harapan dan peluang yang sangat besar, sehingga perlu dilakukan pengelolaan yang baik. Dalam pandangan Azizah (2014), manajemen pesantren dilakukan sebagai sebuah proses untuk meningkatkan aset dan kemampuan bidang ekonomi menuju keswadayaan dan kemandirian. Manajemen ini menjadi penting karena beberapa faktor. Pertama, mayoritas penduduk Indonesia adalah muslim dengan komposisi $56 \%$ di perdesaan dan sisanya di perkotaan (BPS, 2010). Sedangkan pesantren adalah media yang paling dekat dengan masyarakat sesuai dengan 
karakteristiknya mayoritas berada di perdesaan. Kedua, pesantren memiliki kekuatan nilai-nilai yang bersumber pada ilahiyyah dan insaniyah yang mampu menggerakkan perubahan sosial (Weber, 1930 dalam Suwito, 2008), sehingga mampu memberikan basis pada perkembangan ekonomi. Ketiga, menurut Halim dkk (2009) bahwa secara umum kondisi sosial dan ekonomi pesantren masih sangat lemah karena baru tahap perkembangan (Kompri, 2018) sehingga dibutuhkan manajemen yang kuat dalam menjalankan usaha ekonomi pesantren.

Besarnya pesantren yang berusaha pada sektor pertanian tentu membutuhkan sarana dan prasarana yang baik. Selain itu juga membutuhkan wadah (lembaga) yang akuntabel dan terpercaya sehingga mudah diterima oleh masyarakat. Pusat Pelatihan Pertanian Perdesaan Swadaya (P4S) dapat menjadi alternatif pilihan. Dalam Peraturan Menteri Pertanian Nomor, 33 tahun 2016 disebutkan, bahwa P4S adalah kelembagaan pelatihan dengan metode permagangan pertanian dan perdesaan yang didirikan, dimiliki, dan dikelola oleh pelaku utama dan pelaku usaha secara swadaya baik perorangan maupun kelompok. Dewi dan Marbun (2006) menambahkan bahwa P4S bukan milik pemerintah. P4S dicirikan dengan: (a) memiliki keunggulan dalam melakukan usaha tani perdesaan dan kesukarelaan berbagi pengetahuan, teknologi dan keterampilan kepada pelaku utama dan/atau pelaku usaha lain yang ditumbuhkembangkan oleh pelaku utama dan/atau pelaku usaha, (b) mempunyai lahan usaha tani dan/atau kegiatan agribisnis perdesaan yang layak dipelajari, (c) melayani masyarakat untuk kegiatan berlatih, magang, berkonsultasi dan/atau kunjungan/studi banding, (d) berada di lingkungan usaha tani atau perdesaan yang mendukung proses belajar mengajar untuk peserta, dan (e) memiliki instruktur/pelatih, fasilitator lainnya yang profesional (Kementan, 2016).

Widoyoko dkk dalam Jatnika (2016) menguraikan, setidaknya ada lima keunggulan kelembagaan P4S, yaitu: 1). pembelajaran diselenggarakan secara lebih terstruktur dan sistematis; 2). bahan materi disesuaikan dengan kebutuhan petani pembelajar; 3). petani belajar secara nyata dan mampu memecahkan masalah yang dihadapi di lapangan; 4). alih teknologi di antara sesama petani (pembelajar dan fasilitator) dapat berjalan lebih efektif dan efisien, dan 5). setelah belajar di P4S, petani pembelajar 


\section{KINERJA PUSAT PELATIHAN PERTANIAN PERDESAAN SWADAYA \\ BERBASIS PESANTREN DI JAWA BARAT \\ Solihin, Iwan Setiawan, Eliana Wulandari}

dipersiapkan langsung dapat bekerja di lahan usaha taninya.

Pada tataran implementasi, permasalahan yang dihadapi P4S juga tidak kalah pelik dengan problematika yang di hadapi pesantren. Di antaranya sekian banyak problematika itu adalah ketergantungan P4S terhadap bantuan pemerintah, keterbatasan jejaring kemitraan, bagaimana menjaga kontinuitas usaha, pemasaran produk, serta diversifikasi usaha. Tanpa itu semua, maka P4S tidak akan mampu menjalankan fungsi intinya, yaitu pemberdayaan masyarakat dan pengembangan sumberdaya manusia pertanian. Oleh sebab itu, penelitian ini bertujuan untuk menganalisa peran dan kinerja P4S berbasis pesantren di Jawa Barat.

\section{METODE PENELITIAN}

\section{Lokasi dan Waktu}

Pengelitian ini dilakukan di Provinsi Jawa Barat dengan mempertimbangkan kekhasan P4S berbasis pesantren di setiap kabupaten. Waktu penelitian dilaksanakan pada bulan Maret dan April tahun 2019.

\section{Rancangan Penelitian}

Penelitian ini menggunakan pendekatan kuantitatif dengan menggunakan metode survei.

\section{Variabel Penelitian}

Variabel yang diukur yaitu peran P4S yang terdiri dari peran pelatihan, penyuluhan, regenerasi petani, diseminasi, dan pengembangan jejaring. Kinerja P4S terdiri dari tingkat keswadayaan, kemitraan, kemanfaatan, keterpaduan, dan keberlanjutan. Skala yang digunakan adalah skala berjenjang modifikasi dari skala likert yakni skala yang diukur dari pernyataan sikap, persepsi dan tanggapan lain dengan kategori ordinal yang diperingkatkan sepanjang kontinum. Interval skala yang digunakan dalam penelitian ini berkisar antara satu (1) yang berarti lemah, dua (2) yang berarti sedang, tiga (3) yang berarti kuat. Proses transformasi dilakukan dengan mengubah data ordinal menjadi interval dengan selang indek transformasi skor 0-100. Berdasarkan transformasi tersebut dibagi menjadi tiga kategori rendah pada skor $<35$, sedang dengan skor 36-68, dan tinggi dengan skor $>69$. 


\section{Teknik Penarikan Sampel}

Teknik pengambilan sampel menggunakan Proporsionate Strafied random sampling, di Kabupaten Bandung dan Garut. Kedua kabupaten tersebut memiliki populasi berjumlah 215 orang. Selanjutnya penentuan sampel menggunakan rumus Slovin dari populasi anggota P4S di dua Kabupaten tersebut sehingga didapatkan 140 sampel (P4S Al Hidayah 26 orang, P4S Ikamaja Terpadu 36 orang, P4S Al Muhlis 38 orang, dan P4S Al Ittifaq 40 orang).

\section{Teknik Pengumpulan Data}

Data primer dikumpulkan langsung dari anggota P4S dengan teknik wawancara menggunakan panduan kuesioner dan observasi di lapangan serta wawancara mendalam kepada ketua atau pengurus P4S untuk mengkonfirmasi hasil dari anggota P4S. Data sekunder diperoleh dari pencatatan data yang sudah tersedia di instansi yang terkait dengan fokus penelitian.

\section{Rancangan Analisis Data}

Teknik analisis data yang digunakan dalam penelitian ini adalah statistik deskriptif.

\section{HASIL DAN PEMBAHASAN}

\section{Karakteristik Responden}

Umur responden $\mathrm{P} 4 \mathrm{~S}$ berbasis pesantren mayoritas berusia pertengahan (30-50 tahun) dengan rata-rata usia 47 tahun, hal ini berarti mayoritas berada pada usia produktif dalam bekerja. Haryanto dkk (2017) menyebut bahwa usia ini dicirikan kedinamisan yaitu dengan banyak mencari peluang dan informasi menguntungkan yang berhubungan dengan peningkatan kesejahteraan dan pencarian prestise diri. Responden rata-rata menyelesaikan pendidikan formal di Sekolah Menengah Pertama, namun untuk pendidikan non formal (penerangan singkat, penyuluhan, pelatihan, magang, dan SLPHT/SLI/SLB/SLPTT), mayoritas responden pernah mengikuti atau mendapatkan penyuluhan. Jika diperdalam, rata-rata responden pernah mengikuti lebih dari satu kegiatan pendidikan non formal, 27,1 persen pernah mengikuti tiga kegiatan (penerangan, penyuluhan, dan pelatihan), hal ini menandakan bahwa rata-rata responden terbuka dengan informasi dari luar. Karakteristik responden P4S berbasis pesantren disajikan pada Tabel 1. 


\section{KINERJA PUSAT PELATIHAN PERTANIAN PERDESAAN SWADAYA \\ BERBASIS PESANTREN DI JAWA BARAT \\ Solihin, Iwan Setiawan, Eliana Wulandari}

Tabel. 1. Sebaran responden berdasarkan karakteristik responden tahun 2019

\begin{tabular}{|c|c|c|c|}
\hline \multirow[t]{2}{*}{$\begin{array}{c}\text { Potensi } \\
\text { Internal }\end{array}$} & \multirow[t]{2}{*}{ Kategori } & \multirow[t]{2}{*}{$\begin{array}{c}\text { Ora } \\
\text { ng }\end{array}$} & $\begin{array}{l}\text { Respon } \\
\text { den } \\
n=140\end{array}$ \\
\hline & & & $\%$ \\
\hline \multirow{4}{*}{ Umur } & Remaja (<20 th) & 1 & 0,7 \\
\hline & Dewasa Awal (20 -30 th) & 17 & 12,1 \\
\hline & $\begin{array}{l}\text { Usia Pertengahan ( } 30 \text { - } \\
50 \text { th) }\end{array}$ & 76 & 54,3 \\
\hline & Usia Lanjut ( $>50$ th) & 45 & 32,1 \\
\hline \multirow{5}{*}{$\begin{array}{l}\text { Pendidikan } \\
\text { Formal }\end{array}$} & Tidak Sekolah & 3 & 2,1 \\
\hline & SD Sederajat & 41 & 29,3 \\
\hline & SMP Sederajat & 53 & 37,9 \\
\hline & SMU Sederajat & 34 & 24,3 \\
\hline & $>\mathrm{D} 3$ & 9 & 6,4 \\
\hline \multirow{5}{*}{$\begin{array}{l}\text { Pendidikan } \\
\text { Non formal }\end{array}$} & Penerangan & 78 & 55,7 \\
\hline & Penyuluhan & 107 & 76,4 \\
\hline & Pelatihan & 102 & 72,9 \\
\hline & Magang & 39 & 27,9 \\
\hline & SLPHT/SLI/SLB/SLPTT & 34 & 24,3 \\
\hline \multirow{4}{*}{$\begin{array}{l}\text { Pengalaman } \\
\text { Bertani }\end{array}$} & $<10$ Tahun & 58 & 41,4 \\
\hline & 11-20 Tahun & 39 & 27,9 \\
\hline & 21-30 Tahun & 29 & 20,7 \\
\hline & $>30$ Tahun & 14 & 10,0 \\
\hline \multirow{3}{*}{ Tanggungan } & $<3$ Jiwa & 59 & 42,1 \\
\hline & 3-6 Jiwa & 74 & 52,9 \\
\hline & $>6$ Jiwa & 7 & 5,0 \\
\hline \multirow{3}{*}{$\begin{array}{l}\text { Status } \\
\text { Garapan }\end{array}$} & Milik Sendiri & 70 & 50,0 \\
\hline & Sewa & 25 & 17,9 \\
\hline & Garap & 39 & 27,9 \\
\hline \multirow{5}{*}{$\begin{array}{l}\text { Tinggkat } \\
\text { Penghasilan } \\
\text { setelah } \\
\text { bergabung } \\
\text { P4S }\end{array}$} & Berkurang & 2 & 1,4 \\
\hline & Tetap & 32 & 22,9 \\
\hline & Bertambah & 81 & 57,9 \\
\hline & Bertambah Banyak & 17 & 12,1 \\
\hline & Berlipat-lipat & 8 & 5,7 \\
\hline
\end{tabular}

Sumber: Analisis Data Primer (2019)

\section{Peran P4S Berbasis Pesantren}

Peran P4S sebagaimana disebutkan oleh Kementerian Pertanian (2016) adalah pelatihan, penyuluhan, regenerasi petani, berbagai kegiatan diseminasi, dan pengembangan jejaring. Hasil analisis data responden terhadap peran $\mathrm{P} 4 \mathrm{~S}$ berbasis pesantren disajikan pada Tabel

2.

Tabel. 2. Klasifikasi dan persentasi peran $\mathbf{P} 4 \mathrm{~S}$ berbasis pesantren di Jawa Barat, 2019

\begin{tabular}{|c|c|c|c|}
\hline Peran P4S & $\begin{array}{l}\text { Klasifikasi } \\
\text { (skor) }\end{array}$ & Orang & $\begin{array}{c}\text { Responden } \\
\text { n=140 } \\
\%\end{array}$ \\
\hline \multirow{3}{*}{ Pelatihan } & Tinggi & 92 & 66 \\
\hline & Sedang & 36 & 26 \\
\hline & Rendah & 12 & 8 \\
\hline \multirow{3}{*}{ Penyuluhan } & Tinggi & 96 & 69 \\
\hline & Sedang & 31 & 22 \\
\hline & Rendah & 12 & 9 \\
\hline \multirow{3}{*}{ Regenerasi Petani } & Tinggi & 86 & 62 \\
\hline & Sedang & 38 & 27 \\
\hline & Rendah & 16 & 11 \\
\hline \multirow{3}{*}{ Diseminasi } & Tinggi & 67 & 48 \\
\hline & Sedang & 33 & 24 \\
\hline & Rendah & 39 & 28 \\
\hline \multirow{3}{*}{$\begin{array}{l}\text { Pengembangan } \\
\text { Jejaring }\end{array}$} & Tinggi & 80 & 57 \\
\hline & Sedang & 37 & 27 \\
\hline & Rendah & 23 & 17 \\
\hline
\end{tabular}

Sumber: Analisis Data Primer (2019)

Penyelenggaraan pelatihan adalah yang mendasar bagi P4S, sebab salah satu latar belakang kelahiran P4S adalah untuk berbagi kesuksesan bagi sesama petani melalui pelatihan dan permagangan. Jatnika (2016) menyebut bahwa P4S mempunyai peran sebagai lembaga/organisasi pembelajaran (learning organization) sekaligus sebagai pembaharu/pelopor (agent of change) dalam rangka pemberdayaan dan kemandirian sumberdaya manusia petani sebagai pelaku utama dan pelaku usaha pembangunan pertanian. Hal ini 
diperkuat oleh Abbas (2014) bahwa proses pembelajaran di P4S dilakukan melalui metode magang yang mengedepankan prinsip "belajar melalui berkerja" dengan pendekatan petani belajar dari petani.

Secara agregat peran pelatihan berada pada kategori sedang sebesar 66 persen. Hal ini berarti secara umum P4S telah menyelenggarakan pelatihan, namun belum sepenuhnya berjalan maksimal. Hal ini terjadi dikarenakan beberapa faktor, diantaranya adalah keterbatasan instruktur, fasilitator, kesiapan kurikulum, modul, kekhasan pelatihan $\mathrm{P} 4 \mathrm{~S}$, dan sarana prasarana. Bahkan jika dilihat secara parsial, $\mathrm{P} 4 \mathrm{~S}$ al Hidayah sampai saat ini belum menjalankan perannya untuk melatih.

Peran penyuluhan P4S dimaksudkan agar P4S mampu menjadi lembaga yang turut andil menyelenggarakan penyuluhan dan pendampingan bagi pelaku utama dan pelaku usaha. Tabel 1 memperlihatkan bahwa peran penyuluhan $\mathrm{P} 4 \mathrm{~S}$ berada pada kategori tinggi sebesar 69 persen. Hal ini ini menggambarkan bahwa P4S telah melakukan penyuluhan bagi petani anggota atau bahkan petani sekitar. Kesuksesan P4S menyelenggarakan penyuluhan bukan karena kegiatan penyuluhan semata dan P4S secara kelembagaan. Sebab, pada hakikatnya kegiatan penyuluhan ini sepenuhnya didukung kegiatan pelatihan, pendidikan, dan bahkan penerapan hasil penelitian dari lembaga terkait. Indraningsih (2016) menyebutnya karena adanya keterkaitan dan sinergi antara penelitian, pelatihan, pendidikan dan penyuluhan.

Terkait dengan regenerasi petani dimaksudkan agar P4S secara kelembagaan turut andil dalam menumbuhkan, mengembangkan dan memperkuat kader tani. Peran berikutnya adalah menjadi sentra pengembangan dan diseminasi teknologi/inovasi, budidaya, perbenihan, pengolahan hasil, dan pengembangan spesifik lokalita. Peran terakhir yang dapat dilakukan oleh P4S adalah memiliki kemampuan mengembangkan jejaring usaha tani. Secara sederhana Abbas dkk (2014) menyebutkan bahwa P4S diharapkan mampu menciptakan akselerasi informasi dan teknologi, menjadi sentra pelayanan informasi dan teknologi, serta menjadi pusat komunikasi dan konsultasi petani.

Secara agregat, tiga peran terakhir berada pada kategori sedang, dengan besaran antara 48-62 persen. Hal ini menggambarkan bahwa pada ketiga peran tersebut $\mathrm{P} 4 \mathrm{~S}$ berbasis pesantren 


\section{KINERJA PUSAT PELATIHAN PERTANIAN PERDESAAN SWADAYA \\ BERBASIS PESANTREN DI JAWA BARAT \\ Solihin, Iwan Setiawan, Eliana Wulandari}

tidak maksimal menjalankannya.

Diantara faktor yang mempengaruhinya adalah dikarenakan secara kelembagaan, P4S hanya fokus pada kegiatan usaha tani, pelatihan, dan magang.

\section{Kinerja P4S Berbasis Pesantren}

Kinerja P4S berbasis pesantren secara global sebagian berkinerja dalam kategori tinggi dan sebagian berkinerja dalam kategori sedang. Hasil ini menggambarkan bahwa P4S berbasis pesantren secara umum belum berkinerja secara optimal. Kinerja P4S berbasis pesantren diukur dengan indikator tingkat keswadayaan, kemitraan, kemanfaatan, keterpaduan, dan keberlanjutan. Kinerja P4S berbasis pesantren disajikan pada Tabel 3.

Terkait dengan keswadayaan, dimaksudkan agar kelembagaan pelatihan pertanian swadaya dikembangkan untuk meningkatkan kemampuan, peran dan kemandirian lembaga. Abbas dkk (2014) menyebutnya dapat menolong diri sendiri serta memilki kemandirian berbasis kearifan lokal. Secara umum tabel.3 di atas menunjukkan bahwa $\mathrm{P} 4 \mathrm{~S}$ hanya mampu mendorong keswadayaan anggota pada taraf sedang, kecuali pada P4S Terpadu Ikamaja. Hal ini sekaligus juga mengisyaratkan dan menegaskan bahwa secara umum $\mathrm{P} 4 \mathrm{~S}$ berbasis pesantren masih sangat tergantung dengan institusi eksternal.

Tabel. 3. Klasifikasi dan persentasi kinerja P4S berbasis pesantren di Jawa Barat, 2019

\begin{tabular}{|c|c|c|c|c|c|}
\hline \multirow{4}{*}{$\begin{array}{c}\text { Kinerja } \\
\text { P4S }\end{array}$} & \multirow{4}{*}{$\begin{array}{c}\text { Klasifi- } \\
\text { kasi } \\
\text { (skor) }\end{array}$} & \multicolumn{2}{|c|}{ Kab. Garut } & \multicolumn{2}{|c|}{ Kab. Bandung } \\
\hline & & \multicolumn{4}{|c|}{ P4S } \\
\hline & & $\begin{array}{c}\text { Al } \\
\text { Hida- } \\
\text { yah } \\
\mathbf{n}=\mathbf{2 6}\end{array}$ & $\begin{array}{c}\text { Terpadu } \\
\text { Ikamaja } \\
\mathbf{n}=36\end{array}$ & $\underset{\mathbf{n}=\mathbf{3 8}}{\underset{\text { Muhlis }}{\text { Al }}}$ & $\begin{array}{c}\text { Al } \\
\text { Itti- } \\
\text { faq } \\
\text { n=4 } \\
0\end{array}$ \\
\hline & & $\%$ & $\%$ & $\%$ & $\%$ \\
\hline \multirow{3}{*}{$\begin{array}{l}\text { Keswada } \\
\text { yaan }\end{array}$} & Tinggi & 50 & 87 & 55 & 56 \\
\hline & Sedang & 26 & 9 & 36 & 41 \\
\hline & Rendah & 24 & 4 & 9 & 4 \\
\hline \multirow{3}{*}{$\begin{array}{l}\text { Kemitraa } \\
\mathrm{n}\end{array}$} & Tinggi & 44 & 84 & 48 & 54 \\
\hline & Sedang & 31 & 10 & 35 & 35 \\
\hline & Rendah & 25 & 6 & 18 & 11 \\
\hline \multirow{3}{*}{$\begin{array}{l}\text { Kemanfa } \\
\text { atan }\end{array}$} & Tinggi & 37 & 87 & 56 & 56 \\
\hline & Sedang & 34 & 11 & 33 & 36 \\
\hline & Rendah & 29 & 2 & 11 & 7 \\
\hline \multirow{3}{*}{$\begin{array}{l}\text { Keterpad } \\
\text { uan }\end{array}$} & Tinggi & 52 & 88 & 58 & 56 \\
\hline & Sedang & 23 & 10 & 33 & 40 \\
\hline & Rendah & 25 & 3 & 9 & 4 \\
\hline \multirow{3}{*}{$\begin{array}{l}\text { Keberlanj } \\
\text { utan }\end{array}$} & Tinggi & 54 & 87 & 55 & 82 \\
\hline & Sedang & 25 & 10 & 32 & 17 \\
\hline & Rendah & 21 & 3 & 14 & 1 \\
\hline
\end{tabular}

Sumber: Analisis Data Primer (2019)

Terkait dengan kemitraan, Kementan (2016) menyebut bahwa P4S merupakan mitra kerja pemerintah dan stakeholder dalam mengembangkan sumber daya manusia pertanian. Secara umum pada aspek ini hanya P4S Ikamaja terpadu yang berada pada kategori berkinerja tinggi, sedangkan yang lainnya masih pada taraf sedang.

Terkait dengan aspek kemanfaatan, $\mathrm{P} 4 \mathrm{~S}$ berbasis pesantren secara 
kelembagaan diharapkan dapat memberikan manfaat kepada pelaku utama, pelaku usaha dan masyarakat secara luas (Kementan, 2016). Pada aspek ini, hanya P4S Terpadu Ikamaja yang berkinerja pada taraf tinggi dan sisanya berkinerja pada taraf sedang. Hal ini mengisyaratkan bahwa keberadaan P4S belum maksimal dirasakan kemanfaatannya oleh stakeholders.

Keterpaduan yang dimaksudkan oleh Kementan (2016) adalah bahwa proses penumbuhan dan pengembangan P4S merupakan bagian integral pembangunan pertanian dan perdesaan secara serasi dan sinergi. Pada aspek ini hanya P4S Terpadu Ikamaja yang berkinerja tinggi, sedangkan yang lain berkinerja pada taraf sedang. Hasil ini menggambarkan bahwa kegiatan P4S belum sepenuhnya sejalan dan searah dengan program pembangunan pertanian yang diusung oleh pemerintah. Di antara faktor penghambat sinergitas kegiatan P4S dengan pemerintah adalah; pertama. Lemahnya kemampuan sumber daya yang dimiliki oleh P4S yang berakibat pada lambatnya P4S membaca arah kebijakan pemerintah. Sulistio (2010) menyebut bahwa setidaknya setiap orang idealnya memiliki tiga kemampuan, yaitu kemampuan teknis (technical skill), kemampuan hubungan manusia (human relation skill) dan kemampuan manajerial (managerial skill). Kedua. Cepat berubahnya kebijakan dan program pemerintah (Kementan) dengan minimnya sosialisasi. Hal inilah yang diakui dan dirasakan oleh sebagian pengelola $\mathrm{P} 4 \mathrm{~S}$ berbasis pesantren.

Pembangunan berkelanjutan sangatlah penting pada semua aspek kehidupan manusia, oleh sebab itu maka pada tahun 1992, semua pemimpin dunia bertemu dalam konferensi dunia di Rio de Janeiro, Brasil yang membahas konsep pembangunan berkelanjutan untuk semua aspek kehidupan sosial, ekonomi, budaya dan lingkungan yang terkenal dengan nama Agenda 21. Salah satu agenda 21 yang berkaitan langsung dengan sektor pertanian adalah program Sustainable Agriculture and Rural Development (SARD). Pertanian berkelanjutan (sustainable agriculture) merupakan prinsip dasar pembangunan pertanian seluruh dunia, termasuk di Indonesia.

Srageldin dalam Rivai dan Anugrah (2011) menyebut bahwa dalam kerangka segitiga konsep pembangunan berkelanjutan, suatu kegiatan pembangunan (termasuk pertanian dan agribisnis) dinyatakan berkelanjutan, jika kegiatan tersebut secara ekonomis, 


\section{KINERJA PUSAT PELATIHAN PERTANIAN PERDESAAN SWADAYA \\ BERBASIS PESANTREN DI JAWA BARAT \\ Solihin, Iwan Setiawan, Eliana Wulandari}

ekologis dan sosial bersifat berkelanjutan.

Secara riil disajikan pada Gambar 1.

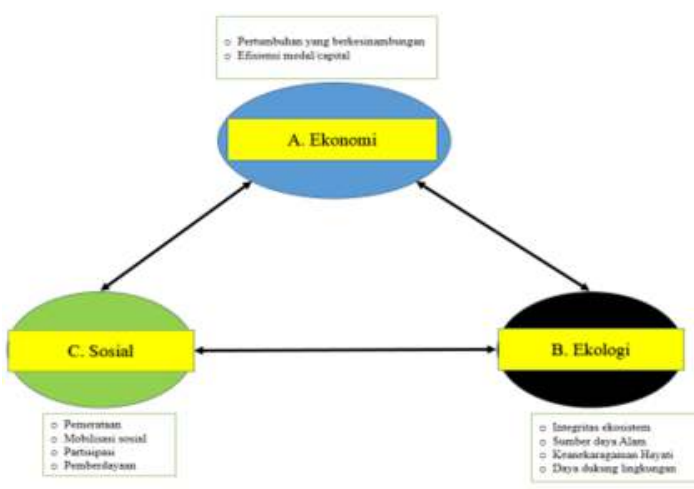

Gambar 1. Kerangka Segitiga Konsep Pembangunan Berkelanjutan (Enviromentally Sustainable Development Triangle-World Bank, Serageldin and Steer, 1994 dalam Rivai dan Anugrah, 2011)

Secara ekonomis, berkelanjutan dimaksudkan bahwa suatu kegiatan pembangunan harus dapat membuahkan pertumbuhan ekonomi, pemeliharaan modal (capital maintenance), penggunaan sumber daya, dan investasi secara efisien. Sedangkan pada aspek ekologis, berkelanjutan dimaksudkan bahwa kegiatan pertanian harus dapat mempertahankan integritas ekosistem, memelihara daya dukung lingkungan dan konservasi sumber daya alam termasuk keanekaragaman hayati (biodiversity). Adapun berkelanjutan secara sosial dimaksudkan bahwa suatu kegiatan pembangunan pertanian hendaknya dapat menciptakan pemerataan hasil-hasil pembangunan, mobilitas sosial, kohesi sosial, dan pengembangan kelembagaan.

Sedangkan aspek keberlanjutan yang dimaksud oleh Kementan (2016) adalah bahwa secara kelembagaan kegiatan-kegiatan P4S dilaksanakan secara terarah dan sistematis guna mencapai kemandirian. Pada aspek ini, P4S Terpadu Ikamaja dan Al Ittifaq berkinerja pada kategori tinggi, sedangkan P4S Al Hidayah dan al Muhlis berkinerja pada taraf sedang. P4S yang berkinerja tinggi pada aspek ini disebabkan terpenuhinya parameter segitiga pembangunan pertanian. Pada P4S Terpadu Ikamaja sangat memperhatikan aspek pemenuhan kesejahteraan anggota dengan beternak sapi yang pola penjualanya diatur oleh P4S, sehingga meminimalisir jatuhnya harga. Kotoran sapi yang ada kemudian diolah menjadi pupuk organik sebagai bagian dari pengelolaan lingkungan. Kemudian pupuk organik tersebut dibagi secara gratis untuk anggota dan masyarakat sekitar, sehingga memperingan biaya produksi petani binaan. Hal yang demikian juga berlaku bagi P4S al Ittifaq. P4S Terpadu Ikamaja yang secara parsial pada keseluruhan indikator berkinerja pada kategori tinggi dengan rata-rata 86 persen. Sedangkan 
P4S al Ittifaq hanya berkinerja tinggi pada indikator keberlanjutan. Namun secara agregat terhadap seluruh indikator, P4S berbasis pesantren berkinerja pada taraf sedang, dengan rata-rata sebesar 62 persen.

\section{KESIMPULAN DAN SARAN}

Peran Pusat Pelatihan Pertanian Perdesaan Swadaya (P4S) berbasis pesantren secara umum telah berperan dalam kategori sedang untuk seluruh peran, kecuali peran penyuluhan. Kurang maksimalnya $\mathrm{P} 4 \mathrm{~S}$ menjalankan peranperan tersebut disebabkan karena keterbatasan sumberdaya dan sarana prasarana yang dimiliki oleh P4S.

Secara agregat, kinerja P4S berbasis pesantren dalam kategori sedang dengan rata 62 persen. Namun secara parsial, P4S Terpadu Ikamaja berkinerja tinggi pada semua indikator yang diukur dengan rata-rata 86 persen. Sedangkan P4S Al Ittifaq berkinerja tinggi hanya pada indikator keberlanjutan.

\section{DAFTAR PUSTAKA}

Abbas, S., Rida, S., \& Dewi, G. (2014). Peran Pusat Pelatihan Pertanian dan Perdesaan Swadaya (P4S) Dalam Mencerdaskan Petani. Jakarta. Yayasan Amal Masyarakat Pertanian Indonesia. Cetakan Pertama.
Azizah, N. S. (2014). Pengelolaan Unit Usaha Pesantren Berbasis Ekoproteksi. Yogyakarta: Jurnal Ekonomi dan Bisnis Islam, (1).

Coelli, T.R \& Battese, G.E. (2005). An Introduction to Efficieny and Productivity Analysis. Kluwer Academic Publishers, BostonDordrecht-London.

Dhofier, Z. (2011). Tradisi Pesantren (Studi Pandangan Hidup Kiai dan Visinya Mengenai Masa Depan Indonesia). Jakarta: LP3S. Cetakan pertama.

Haryanto, Y., Sumardjo, Amanah, S., \& Pranoto, P.C. (2017). Efektivitas Peran Penyuluh Swadaya Dalam Pemberdayaan Petani Di Provinsi Jawa Jurnal Pengkajian dan Pengembangan Teknologi Pertanian, 20(2): 141-154.

Indraningsih, K.S. (2016). Keterkaitan Penelitian, Pendidikan, Pelatihan, Dan Penyuluhan Dalam Diseminasi Inovasi Teknologi Pertanian. Prosiding Seminar Nasional Perlindungan dan Pemberdayaan Pertanian dalam Rangka Pencapaian Kemandirian Pangan Nasional dan Peningkatan Kesejahteraan Petani. Pusat Sosial Ekonomi dan Kebijakan Pertanian Jl. A. Yani No.70, Bogor 16161.

International Fund for Agricultural Development. (2013). IFAD and Public-Private Partnerships: Selected Project Experiences. Rome: IFAD.

Jatnika, A. (2016). Peran Kluster Kompetensi Petani fasilitator Yang Dimoderasi Empati Terhadap Efektivitas Pusat Pelatihan Pertanian Dan Perdesaan Swadaya Di Provinsi Jawa Barat. Disertasi pada Sekolah Pascasarjana Universitas Gadjah Mada Yogyakarta. 


\section{KINERJA PUSAT PELATIHAN PERTANIAN PERDESAAN SWADAYA \\ BERBASIS PESANTREN DI JAWA BARAT \\ Solihin, Iwan Setiawan, Eliana Wulandari}

Kompri. (2018). Manajemen Dan Kepemimpinan Pondok Pesantren. Jakarta. Prenadamedia Group. Cetakan pertama.

Rivai, R.S. \& Anugrah, I.S. (2011). Konsep Dan Implementasi Pembangunan Pertanian Berkelanjutan Di Indonesia. Jurnal Forum Penelitian Agro Ekonomi, 29(1): 13-25.

Sulistio, E.B. (2010). Faktor-Faktor Penghambat Pengembangan Sumberdaya Aparatur Pemerintah Daerah. Jurnal Sosialita, 1:1-13.
Suwito, N.S. (2008). Model Pengembangan Ekonomi Pondok Pesantren. Purwokerto: Jurnal Penelitian Pendidikan Agama dan Keagamaan, 6(3):63-85.

Yasid, A dkk. (2018). Paradigma Baru Pesantren; Menuju Pendidikan Islam Transformatif. Yogyakarta. IRCiSoD. Cetakan pertama. 